DOI 10.37882/2223-2982.2020.11.16

\title{
ЗНАЧЕНИЕ ОБРАЗНОГО МЫШЛЕНИЯ В ОБУЧЕНИИ ФИЗИКЕ
}

\section{THE VALUE OF IMAGINATIVE THINKING IN TEACHING PHYSICS}

\section{E. Ilicheva \\ Yu. Ilicheva \\ T. Kholodenina}

Summary: The article deals with the problem of teaching natural science disciplines, and physics in particular, in educational institutions of secondary vocational education. There is a contradiction between the high requirements in physics for the students of SPO technical profile and the actual level of training of first-year students, between the educational potential of physics in professional training of students of technical specialties and insufficient development of methodical technologies to realize that potential in the formation of professional competencies of graduates SPO. To form on this basis, within one academic year, future young specialists will have the knowledge and skills that they will need to study special disciplines and in their future work with traditional methods of training - a task that is almost impossible to achieve. The inharmonious formation of scientific concepts in students is explained by the opposition of the logical method of cognition of reality and the emotional-figurative one. Working with students, teachers pay attention to the development of verbal-logical thinking as the leading type of thinking and actually ignore the rest of its types. Physics has huge opportunities to use imaginative components of teenagers' thinking. The concept of teaching methods based on the use of not only logical, but also imaginative thinking in their relationship is proposed.

Keywords: imaginative thinking, visual image, holistic thinking, teaching methods, stages of information perception, learning process, physical phenomena.
К.n.н., дочент, ГБОУ ВО «Нижегородский государственный инженерно-экономический университет», Воротынеи ele45630334@yandex.ru

Ильичёва Юлия Валерьевна аспирант, ГБОУ ВО «Нижегородский государственный инженерно-экономический университет», Воротынеи

Холоденина Татьяна Сергеевна аспирант, ГБОУ ВО «Нижегородский государственный инженерно-экономический университет», Воротынец

Аннотация: В статье рассматривается проблема преподавания естественнонаучных дисциплин, и физики, в частности, в образовательных учреждениях среднего профессионального образования. Существует противоречие между высокими требованиями по физике для обучающихся СПО технического профиля и реальным уровнем подготовки студентов-первокурсников, между образовательным потенциалом физики в профессиональной подготовке студентов технических специальностей и недостаточной разработанностью методических технологий, позволяющих реализовывать этот потенциал при формировании профессиональных компетенций выпускников СПО. Сформировать на такой основе в течение одного учебного года у будущих молодых специалистов знания и умения, которые им потребуются для изучения спецдисциплин и в дальнейшей трудовой деятельности традиционными методами обучения - задача практически не достижимая. Негармоничное формирование у учеников научных понятий объясняется противопоставлением логического способа познания действительности и эмоционально-образного. Работая со студентами, педагоги уделяют внимание развитию вербально-логического мышления как ведущего типа мышления и фактически игнорируют остальные его типы. Физика имеет колоссальные возможности использования образных компонентов мышления подростков. Предлагается концепт методики преподавания, основанной на использовании не только логического, но и образного мышления в их взаимосвязи.

Ключевые слова: образное мышление, визуальный образ, целостное мышление, методика преподавания, этапы восприятия информации, процесс обучения, физические явления.

В соответствии с примерной программой общеобразовательной учебной дисциплины «Физика» для профессиональных образовательных организаций, рекомендованной ФГАО «Федеральный институт развития образования» [1], содержание программы «Физика» общеобразовательного цикла программ подготовки специалистов среднего звена технического профиля направлено на достижение следующих целей:

- освоение знаний о фундаментальных физических законах и принципах, лежащих в основе современной физической картины мира;

- овладение умениями проводить наблюдения, планировать и выполнять эксперименты, выдвигать гипотезы и строить модели, применять полученные знания по физике для объяснения различных физических явлений и свойств веществ; 
практического использования физических знаний; оценивать достоверность естественнонаучной информации;

- развитие познавательных интересов, интеллектуальных и творческих способностей;

- воспитание убежденности в познании законов природы; использование достижений физики на благо развития человеческой цивилизации;

- готовности к морально-этической оценке использования научных достижений;

- использование приобретенных знаний и умений для решения практических задач повседневной жизни.

Однако подавляющее число первокурсников имеют слабую общеобразовательную подготовку, низкий уровень базовых знаний по курсу общеобразовательной физики, испытывают затруднения элементарного понимания физических законов, явлений и решении задач. К тому же учебный план очень насыщен, включает, помимо общеобразовательных дисциплин, общепрофессиональные, в результате учащиеся сильно загружены. В течение одного учебного года достичь вышеуказанных целей традиционными методами обучения - практически невозможно.

Таким образом, существуют противоречия между

- высокими требованиями по физике для обучающихся СПО технического профиля и реальным уровнем подготовки первокурсников;

- между образовательным потенциалом физики в профессиональной подготовке студентов технических специальностей и недостаточной разработанностью методических технологий, позволяющих реализовывать этот потенциал при формировании профессиональных компетенций выпускников СПО.

Педагоги, работающие в системе СПО, используют в своей работе творческий подход: различные педагогические технологии, активизирующие учебно-познавательную деятельность и создающие мотивацию к учебной и профессиональной деятельности (ИКТ-технологии, IT-технологии и др.). Однако целостной методической системы обучения физике в образовательных учреждениях среднего профессионального образования, решающей вышеуказанные проблемы, не существует, что и определило актуальность данного исследования.

По нашему мнению, существует немаловажная причина негармоничного формирования у учеников научных понятий вообще и физических в частности это противопоставление логического, рационального способа познания действительности эмоционально-образному. Применение в процессе образования образного мышления - важнейший психологический ресурс, значительно влияющий на успех учебной деятельности.

Принято считать, что образование практически полностью основано на развитии вербально-логического мышления, способности формировать однозначный контекст. Однако реальному процессу мышления одновременно присущи как «образная», так и «логическая» составляющая, причём это целостная логика протекания мыслительного процесса. Теоретический тезис о взаимозависимости логических и образных компонентов мышления впервые стал упоминаться в трудах С. Л. Рубинштейна еще с середины XX в. В реальной педагогической практике обойтись без апеллирования к образам, визуализации информации невозможно, о чем все чаще стали говорить в последние 10-15 лет [2-9]. Появились работы, в которых рассматривается роль образного мышления в процессе обучения студентов, в том числе инженерного вуза [10-12]. Подобных работ крайне мало, в основном публикации посвящены использованию наглядно-образного мышления у детей, младших школьников, при изучении изобразительного искусства и т.п., что говорит о недостаточной изученности проблемы использования образного мышления в процессе обучения студентов.

В задачи исследования входило:

- дать теоретическое обоснование методике обучения физике, основанной на использовании целостного мышления;

- выделить этапы формирования научного понятия в рамках предложенной методики.

Теоретическая значимость работы состоит в обосновании позитивного влияния на весь процесс обучения физики формирования физических понятий на основе последовательного создания их образов: зрительного, вербального и знакового. Практическая значимость работы заключается в возможности использования преподавателями алгоритма формирования научного понятия.

Игнорирование образного мышления фактически приводит к тому, что образы используются участниками учебного процесса бессознательно, как бы против желания. Процесс создания образов, конкретные приёмы «перевода» учебного материала в образный вид, а также трансляции образов от учителя учащимся подчас протекает интуитивно и неосознанно. Даже преподаватель очень высокой квалификации не всегда отдаёт себе отчёт в том, какими именно образами он пользуется и как эти образы попадают к учащимся. Педагогический успех во многих случаях строится на удачно найденных приёмах работы с образами.

Ярким примером тому является методика обучения В.Ф. Шаталова. Основа его методики - движение от цело- 
го к частям. Это, а также использование опорных схем позволяло создавать наглядные образы об изучаемых явлениях. Однако сам автор опорным конспектам, как одному элементу из шести, отводил последнее место в своей системе. Результаты его обучения были ошеломляющими, но массового применения методика не получила, т.к. практически никто не смог на должном уровне повторить его результаты. Не объясняется ли этот факт тем, что высокая результативность обучения по системе В. Ф. Шаталова обуславливалась именно системой создания образов, но сам автор не донёс этого своим последователям?

Ещё в 40-х годах XX века Ж. Пиаже обосновал закономерности восприятия и усвоения информации, которая проходит следующие этапы [13]:

- сенсорно-моторный этап (получение информации осязательно) - чем больше информации человек получает на этом этапе, тем более полное представление об объекте сложится у него;

- символьный (образный) этап - формирование образа на основании информации, полученной на первом этапе от органов чувств;

- логический этап - осмысление, понимание информации, полученной на втором этапе;

- лингвистический этап - выражение образно воспринятой, логически осмысленной информации в словах.

Нарушение порядка этапов восприятия и обработки информации ведёт к неэффективности, засорённости мышления, вызывает непонимание предмета. Неудивительно, что большинство учащихся отстаёт в учёбе, ведь им предлагают сразу третий, логический этап процесса мышления.

Физика выражает знания формальным языком. Схемы, формулы, материальные и математические модели и т.д. - арсенал науки, с помощью которого кодируется научное знание. Однако у многих первокурсников не развиты мыслительные операции с символами и отвлеченными понятиями. Физика в понимании учащихся - это наука о формулах и задачах, конструирование которых не связано с реальной действительностью. Большинство учащихся не представляют то, о чём они говорят или пишут. Это создаёт большие трудности: учащиеся усваивают физику формально, в виде словесных выражений, за которыми не стоят образы реальных явлений.

Физика имеет колоссальные возможности использования образных компонентов мышления подростков. Установлено, что представление человеком даже статичных трёхмерных зрительных структур по тексту и другим условным знакам - сложная психологическая. Специфика физических и химических объектов заключается в том, что их сущность раскрывается на невидимом и ненаблюдаемом микроуровне. Визуальный познавательный образ выступает заместителем реального объекта и служит средством сопоставления математических формул с объективной действительностью [14].

Ученик сегодняшний заметно отличается от того, что был 20 лет назад, это, как правило, визуал [15, с. 281]. За время проведения исследования нами была отмечена тенденция постоянного роста числа студентов с преобладанием образного типа мышления. Для выявления типа мышления у обучающихся мы использовали тест Г. Айзенка.

Существуют две фазы в построении познавательного образа. Первая фаза - специально организованная перцептивная деятельность. Её основа - это определенные способы обследования объекта (в физике - это наблюдение, физический эксперимент, моделирование) и применение понятийного аппарата (разнообразных критериев анализа), обеспечивающие многоплановое, многоуровневое восприятие объекта. В результате этой фазы формируются мысленный и вербальный образы изучаемого объекта.

Вторая фаза - создание образа по представлению (в уме) осуществляется преимущественно при отсутствии объекта или модели, его замещающей. Основным содержанием этой деятельности является не столько актуализация прошлых восприятий (они являются лишь исходным материалом), сколько их активное мысленное преобразование, приводящее к созданию образа, отличного от содержания того наглядного материала, на котором он первоначально возник. К мысленному и вербальному образам добавляется знаковый (схемы, формулы).

Структуру понятия как познавательного образа можно представить схемой (рис.1).

Можно долго и подробно рассказывать о физических явлениях в учебном процессе, но мы не будем уверены, что у слушателей сформируется правильный образ получаемой информации. Во-первых, при рассказе задействован только один канал чувственного восприятия. Необходимо задействовать как можно больше других каналов: показать изучаемое явление, а лучше провести его ученикам самостоятельно- тогда будет дополнительно задействовано осязание. Во-вторых, формирование образа на основании информации, полученной на первом этапе, должно происходить целенаправленно, а не стихийно. В этом случае помогают такие приёмы как составление опорных конспектов, эскизы, компьютерное моделирование и т. п.

В логике целостного мышления следует идти от общего к частному, оперируя не только логическим, но и образными видами мышления. Сначала необходимо визу- 


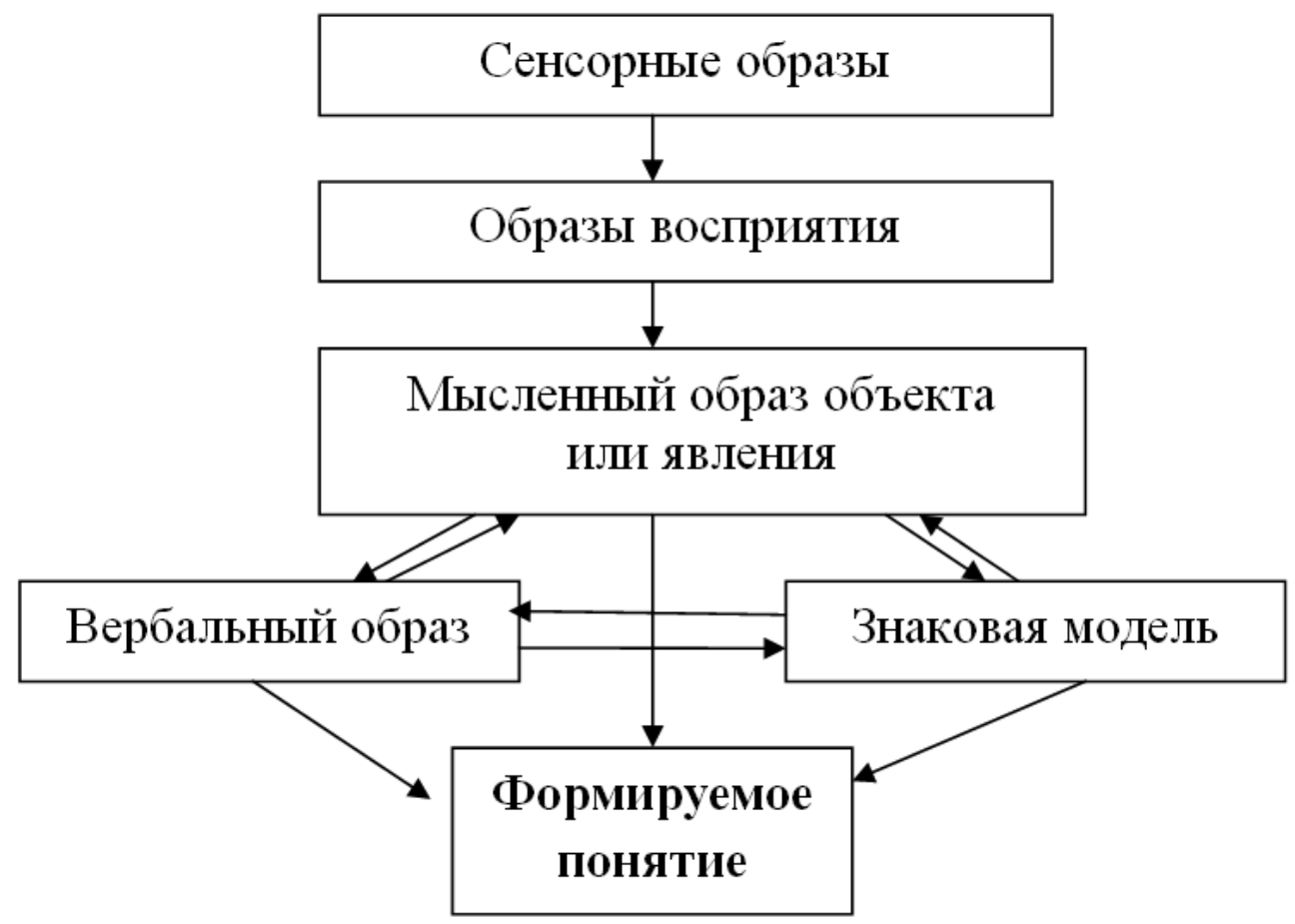

Рис. 1. Структура понятия как познавательного образа

ализировать изучаемое явление, выдвинуть различные гипотезы (создать перцептивный образ). Затем следует мысленно представить изучаемое (создать мысленный образ явления), облечь проделанные действия в физические термины, проговорить (создать вербальный образ), только потом можно обратиться к знаковому описанию, рассмотреть возможные способы составления формул. Данный подход будет являться не алгоритмическим, а основанным на закономерностях восприятия и усвоения информации. В этом случае студентам-логикам будет легче логически осмыслить прочитанное или рассказанное преподавателем, а студенты с преобладающим образным мышлением будут иметь свой способ усвоения информации - через сравнение с образом памяти - и не выпадут из учебного процесса.

Так при использовании понятия «давление газа» обучающийся должен представлять, что такое молекула, причины теплового движения, а также причины, порождающие силу взаимодействия газа со стенками со- суда, в котором он заключён. Только в этом случае он сможет разобраться в рассматриваемом явлении или задаче. Для создания у обучающихся вышеперечисленных представлений необходимо сформировать образы сначала «молекулы» (чаше всего он не создан), затем последовательно: «газообразного состояния», «теплового движения», «расширение газа». В дальнейшем при оперировании понятием «давление» у обучающегося должны в голове возникать, как картинки в мультфильме, все эти образы. Как показывает наш опыт, в этом случае у него создается адекватное понимание понятия «давление газа», а не просто заучивается текст.

Таким образом, разработка методики обучения физики с опорой на образное мышление как важный интеллектуальный ресурс обучающихся является актуальной методической проблемой. Необходимо учить студентов строить образы и оперировать ими, и если ученик не может догадаться, то педагог должен помочь создать образ, адекватный ситуации.

\section{ЛИТЕРАТУРА}

1. Дмитриева В.Ф. Примерная программа общеобразовательной учебной дисциплины «Физика» для профессиональных образовательных организаций. М.: Издательский центр «Академия». 2015. 25 с.

2. Ермак Н.В. Наглядно-образное мышление при решении задач векторной алгебры на клетчатом поле // Актуальные проблемы обучения математике, информатике и естественнонаучным дисциплинам в средней и высшей школе: материалы Всероссийской науч.-практ. конф. 2017. С. 60-62.

3. Пилипец Л.В., Абышева Н.Ю. Развитие наглядно-образного мышления при изучении физики // Современные наукоемкие технологии. - 2016. № 6-1. C. 183-187; URL: http://top-technologies.ru/ru/article/view?id=36004.

4. Чабарова Б.М., Цапцова Т.Н., Абышева Н.Ю., Попова Е.М. Развитие наглядно-образного мышления учащихся основной школы при изучении дисциплин 
естественнонаучного цикла // Современные проблемы науки и образования. 2016. № 3; URL: http://science-education.ru/ru/article/view?id=24800.

5. Скворцов А.В., Комиссарова Т.С. Методика проблематизации учебной информации в преподавательской деятельности // Бизнес. Образование. Право. 2020. № 3(52). С. 373-379.

6. Зорькина 0.В., Шмелькова В.В., Семёнова Л.Ю. Особенности обучения иностранных слушателей подготовительного отделения дисциплинам естественнонаучного цикла (на примере химии) // Вестник Тульского государственного университета. Серия: Современные образовательные технологии в преподавании естественнонаучных дисциплин. 2019. № 1(18). С. 53-56.

7. Калашникова С.Б. Повышение эффективности процесса обучения инженерной графике на основе наглядно-образных и предметно-деятельностных способов // Международное образование и сотрудничество: материалы Междунар. науч.-практ. конф. 2015. Т.3. № 1, С. $34-37$.

8. Кулебакина Д.В. Повышение наглядно-образного мышления посредством использования мультимедийных технологий // Современные научные исследования: актуальные вопросы, достижения и инновации: материалы ХІІ Междунар. науч.-практ. конф: в 3-х частях. 2020. С. 114-117.

9. Dorantes-González D.J. How critical thinking is supported in a flipped learning course // Modern trends in the development of lifelong education: challenges of the digital economy: proceedings of the Int. sci. and pract. conf. 2020. Pp. 37-39.

10. Efremova 0.N., Plotnikova I.V., Ustyuzhanina A.K. Forming Linguistic Competence of Foreign Students at the Preparatory Department of a Technical University. Procedia - Social and Behavioral Sciences // International Education and Cross-Cultural Communication, Problems and Solutions. 2015. Pp. 72-78.

11. Yanushchik O.V., Batbold M., Ustyuzhanina A.K. Improving the Organization of the Learning Process in Mathematics for International Students of Technical Universities. Procedia - social and behavioral sciences // International Education and Cross-Cultural Communication, Problems and Solutions. 2015. Pp. 202-206.

12. Ustyuzhanina A., Plotnikova I., Efremova 0. Business games in Quality control for students of technical universities. Proceedings of 2017 IEEE // Global Engineering Education Conference. DOI: 10.1109/EDUCON.2017.7942822.

13. Пиаже Ж. Речь и мышление ребенка. - М., 1999. - 528 с.

14. Ильичева Е.В., Рябухина Е.В. «Особенности формирования естественнонаучной грамотности у студентов высших учебных заведений направления подготовки «Сервис» // Экономика и предпринимательство. № 8(73), 2016. С. 970-972.

15. Мухортова Д.Д. Типы восприятия и школа // Молодой ученый. 2016. № 17(121). С. 300-301. - URL: https://moluch.ru/archive/121/33384/.

( ) Ильичёва Елена Владимировна (ele45630334@yandex.ru), Ильичёва Юлия Валерьевна, Холоденина Татьяна Сергеевна. Журнал «Современная наука: актуальные проблемы теории и практики»

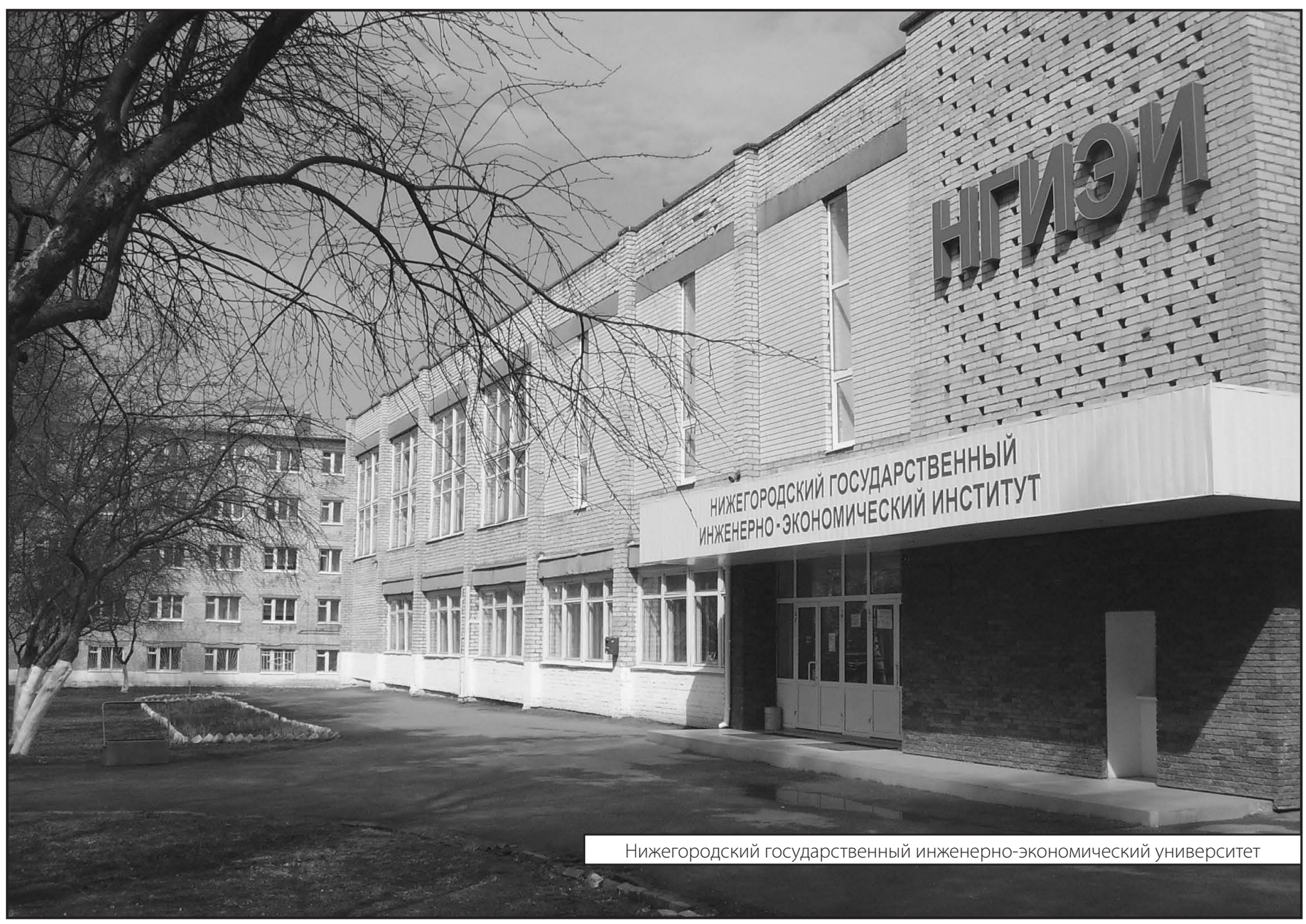

